\title{
COMUNIDADE DE BROMÉLIAS EPIFÍTICAS EM UM FRAGMENTO FLORESTAL URBANO NO SUL DE SANTA CATARINA, BRASIL
}

\author{
EPIPHYTIC BROMELIADS COMMUNITIES IN A URBAN FOREST \\ FRAGMENT IN THE SOUTHERN SANTA CATARINA, BRAZIL
}

\author{
Peterson Teodoro Padilha ${ }^{1}$ \\ Guilherme Alves Elias ${ }^{1}$ \\ Telma Elyta Vilhalba Azeredo ${ }^{2}$ \\ Renato Colares ${ }^{3}$ \\ Altamir Rocha Antunes ${ }^{4}$ \\ Vanilde Citadini-Zanette ${ }^{5}$
}

\section{Resumo}

Este estudo objetivou analisar a diversidade florística da comunidade de bromélias epifíticas em um fragmento florestal urbano no Parque Ecológico Municipal José Milanese no município de Criciúma, sul de Santa Catarina. A flora epifítica de Bromeliaceae foi registrada utilizando-se o método expedito por caminhamento e de quadrantes centrados. A diversidade e frequência foram estimadas pelo número de espécies e pela ocorrência (presença) em cada zona do forófito. Foram registradas as estratégias de polinização e dispersão para cada espécie observada. Para a caracterização da distribuição horizontal foram calculadas as frequências relativas por forófitos e por segmentos de forófitos. Foram registradas 18 espécies de bromeliáceas, sendo 13 espécies pelo levantamento fitossociológico e cinco pelo método de caminhamento. Entre os cinco gêneros encontrados, Tillandsia e Vriesea tiveram o maior número de espécies. A frequência e a riqueza das espécies mostraram diferenças significativas entre fuste e copa. Os valores obtidos por meio da análise de correlação demonstraram que os diâmetros maiores dos forófitos apresentaram maior riqueza de espécies. Estudos aprofundados que visem a levantar a biodiversidade e estrutura das comunidades vegetais são relevantes para propor medidas de conservação destes fragmentos florestais, que mantém grande biodiversidade local.

Palavras-Chave: Biodiversidade, Bromeliaceae, estrutura comunitária, florística.

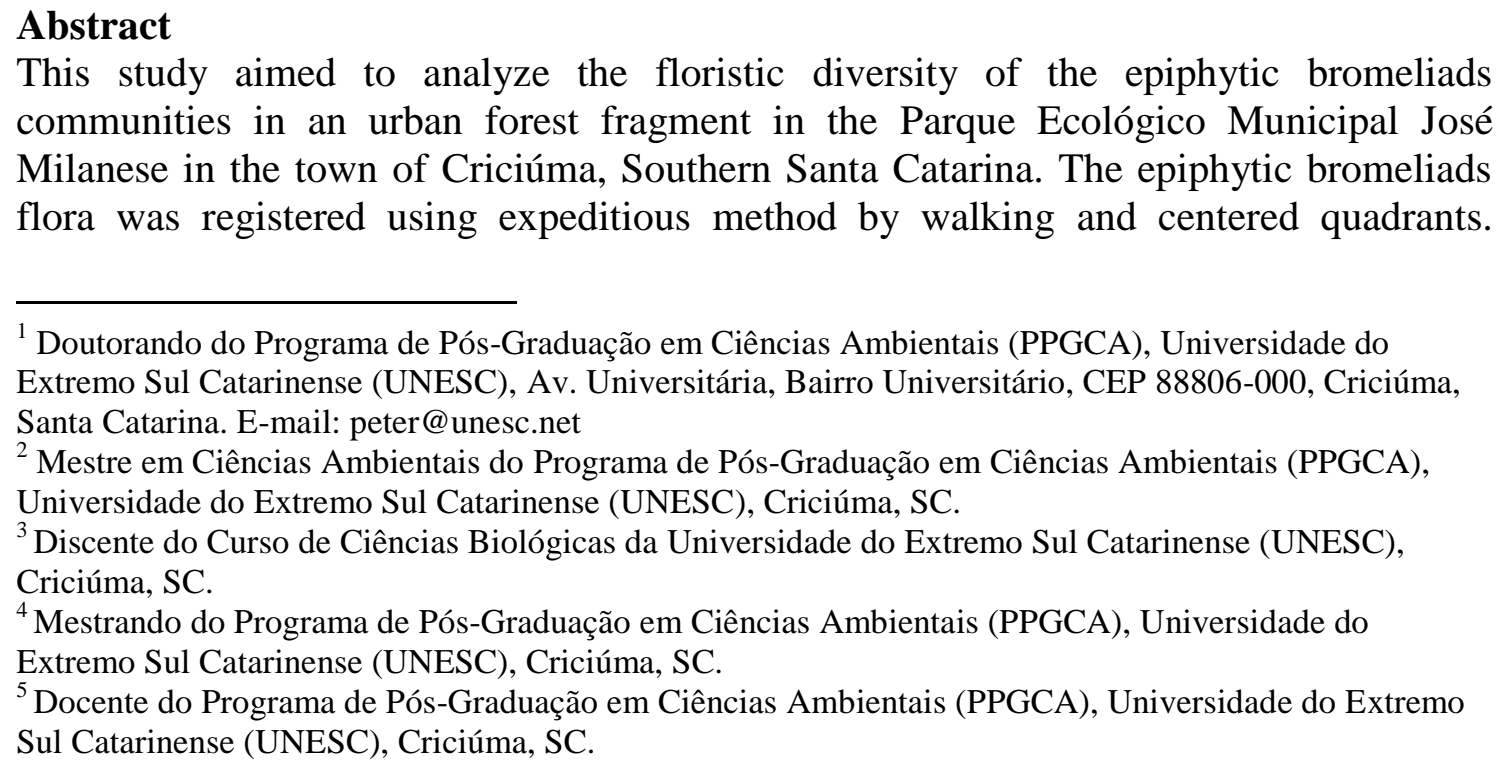

This study aimed to analyze the floristic diversity of the epiphytic bromeliads communities in an urban forest fragment in the Parque Ecológico Municipal José Milanese in the town of Criciúma, Southern Santa Catarina. The epiphytic bromeliads flora was registered using expeditious method by walking and centered quadrants.

\footnotetext{
${ }^{1}$ Doutorando do Programa de Pós-Graduação em Ciências Ambientais (PPGCA), Universidade do Extremo Sul Catarinense (UNESC), Av. Universitária, Bairro Universitário, CEP 88806-000, Criciúma, Santa Catarina. E-mail: peter@unesc.net

${ }^{2}$ Mestre em Ciências Ambientais do Programa de Pós-Graduação em Ciências Ambientais (PPGCA), Universidade do Extremo Sul Catarinense (UNESC), Criciúma, SC.

${ }^{3}$ Discente do Curso de Ciências Biológicas da Universidade do Extremo Sul Catarinense (UNESC), Criciúma, SC.

${ }^{4}$ Mestrando do Programa de Pós-Graduação em Ciências Ambientais (PPGCA), Universidade do Extremo Sul Catarinense (UNESC), Criciúma, SC.

${ }^{5}$ Docente do Programa de Pós-Graduação em Ciências Ambientais (PPGCA), Universidade do Extremo Sul Catarinense (UNESC), Criciúma, SC.
} 
Diversity and frequency were estimated by species number and occurrence (presence) in each phorophyte zone. The strategies of pollination and dispersion were registered for each species. For characterization of the horizontal distribution the relative frequencies were calculated by phorophytes and segments of phorophytes. Eighteen species of bromeliads were registered, 13 species by phytosociological survey and five by walking method. Between the five genus discovered, Tillandsia e Vriesea had the highest number of species. Frequency and species richness showed significant difference between bole and crown. The values obtained by correlation analysis demonstrated that the high diameters of the phorophytes showed high species richness. Detailed studies that aim to sample the biodiversity and structure of plant communities are relevant to propose actions of conservation of these forest fragments that keeps high local biodiversity.

Keywords: Biodiversity, Bromeliaceae, community structure, floristic.

\section{INTRODUÇÃO}

O epifitismo é definido como uma interação ecológica que envolve espécies vegetais em uma relação comensal: uma espécie dependente (epífito) beneficia-se do substrato proporcionado por uma espécie hospedeira (forófito), não diretamente prejudicada por estruturas haustoriais (WAECHTER, 1992).

A flora epifítica mundial é composta por 84 famílias (KRESS, 1986) e aproximadamente entre 23.000 e 29.000 espécies (KERSTEN, 2010; ZOTZ, 2013), principalmente representada por Orchidaceae, Araceae e Bromeliaceae dentre as angiospermas (KERSTEN, 2010).

A família Bromeliaceae, no Brasil, compreende 44 gêneros e 1.348 espécies, sendo 1.180 endêmicas (Flora do Brasil 2020 em construção, 2016). Na Mata Atlântica brasileira foram registrados um total de 31 gêneros, 816 espécies e 150 táxons infraespecíficos, sendo 10 gêneros e 651 espécies endêmicas (STEHMANN et al., 2009).

As bromélias possuem várias de suas espécies adaptadas ao hábito epifítico (GENTRY; DODSON, 1987) ocupando territórios definidos de distribuição, com riqueza destacada para o bioma Mata Atlântica (FONTOURA, 1995; MARTINELLI et al., 2008). As bromélias ocupam todas as faixas de altitude, do nível do mar até os extremos altitudinais, presentes também nas mais diversas condições climáticas, topográficas e pedológicas (MARTINELLI, 2006).

Com base nas principais estratégias adaptativas, o padrão de distribuição espacial das bromélias epifíticas pode variar basicamente em dois sentidos: horizontal: ocorrendo entre diferentes regiões fitogeográficas e forófitos; vertical: podendo variar 
da base até o topo da árvore (estratificação vertical) (REITZ, 1983; ter STEEGE; CORNELISSEN, 1989).

As bromélias epifíticas apresentam grande importância, principalmente nos ambientes tropicais, visto que aumentam a probabilidade de encontros interespecíficos (REITZ, 1983). Além disso, são consideradas um dos nichos ecológicos mais importantes da natureza, pois suas folhas e frutos servem de alimento para alguns herbívoros e insetos, além do consumo humano (PAULA; SILVA, 2004). As flores fornecem néctar para polinizadores vertebrados, principalmente morcegos e beija-flores, sendo uma das poucas famílias em que a polinização por vertebrados predomina sobre a polinização por insetos (ARAÚJO et al., 1994; MARTINELLI, 2006).

São poucos os estudos com Bromeliaceae em Santa Catarina (CAGLIONI et al., 2012; OLIVEIRA et al., 2013; 2014; PADILHA et al., 2015), portanto, tendo em vista a relevância das bromélias na estrutura e dinâmica das florestas, este trabalho objetivou analisar a diversidade florística da comunidade de bromélias epifíticas em um fragmento florestal urbano de Floresta Ombrófila Densa no município de Criciúma, sul de Santa Catarina.

\section{MATERIAL E MÉTODOS}

Área de estudo

O estudo foi realizado no Parque Ecológico Municipal José Milanese (PEMJM), criado com a lei Municipal $n^{\circ} 2.856 / 1993$ (CMC, 2006) a fim de preservar espécies nativas da fauna e flora da Mata Atlântica regional. O PEMJM situa-se no município de Criciúma, sul do estado de Santa Catarina (28 $48^{\circ} \mathrm{S}$ e $49^{\circ} 25^{\prime} \mathrm{W}$, altitude $34 \mathrm{~m}$ ) (Figura 1) e ocupa área total de 7,7 hectares. Destes 5,2 ha são cobertos por Floresta Ombrófila Densa Submontana e 2,5 ha são de uso do Horto Florestal de Criciúma (SILVA, 2006).

Figura 1. Localização do município de Criciúma no estado de Santa Catarina e vista aérea do Parque Ecológico Municipal José Milanese. Fonte: ROCHA (2007). 


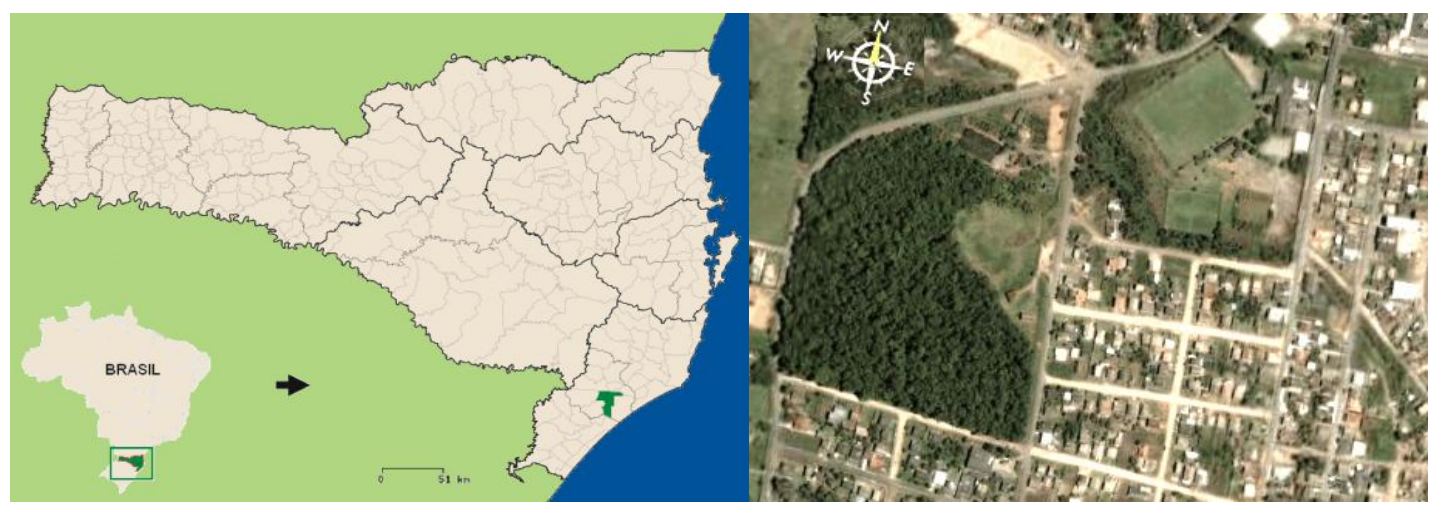

De acordo com o sistema de classificação de Köppen (ALVARES et al., 2014), o clima da região enquadra-se no tipo Cfa (subtropical úmido com verões quentes). A temperatura média anual varia de 17,0 a $19,3^{\circ} \mathrm{C}$, sendo a média das máximas entre 23,4 a $25,9^{\circ} \mathrm{C}$, e das mínimas de 12,0 a $15,1^{\circ} \mathrm{C}$. A média da umidade relativa do ar é de 81,8\%. (EPAGRI; CIRAM, 2001). O solo é classificado como argissolos e alissolos, os quais compreendem 79\% da área do município de Criciúma (EPAGRI-CIRAM, 2001). Na região carbonífera catarinense, a precipitação média é de 1.400 a 1.600 mm/ano, não havendo índices pluviométricos mensais inferiores a 60 mm (BACK, 2009).

Coleta dos dados

A flora epifítica de Bromeliaceae foi registrada utilizando-se o método expedito por caminhamento (FILGUEIRAS et al., 1994) e de quadrantes centrados (COTTAM; CURTIS, 1956). Foram estabelecidos cinco transectos, separados $20 \mathrm{~m}$ entre si. Para cada transecto foram determinados três pontos quadrantes, separados entre si por $10 \mathrm{~m}$, totalizando 60 árvores amostradas. Registrou-se a presença das bromélias nas árvores (forófitos) com diâmetros à altura do peito $(\mathrm{DAP}) \geq 10 \mathrm{~cm}$. Para o estudo da comunidade epifítica, os forófitos foram considerados como unidades amostrais.

O registro das espécies de bromeliáceas epifíticas foi obtido por meio de binóculo, com visualização a partir do solo ou de árvores vizinhas ou ainda com uso de uma escada telescópica de 3,80 m de comprimento. Utilizou-se técnica de escalada ou escalada natural do forófito, quando não foi possível a identificação das espécies com binóculo. Quanto à forma de obtenção de água e nutrientes as espécies foram categorizadas em bromélias-cisterna e bromélias-atmosfera (BENZING, 1990). As estratégias de polinização e de dispersão foram obtidas com base em caracteres morfológicos das flores e das sementes descritas na literatura específica (REITZ, 1983; WANDERLEY; MARTINS, 2007; FISCHER, 1994; MACHADO; SEMIR, 2006). 
Para o estudo da estratificação vertical, os forófitos foram divididos em duas zonas verticais: fuste e copa, segundo Giongo e Waechter (2004), considerando copa a partir do ponto onde emergem os ramos principais.

As espécies de bromélias foram identificadas tendo como base os trabalhos de Azeredo (2008, 2010) e Reitz (1983), consulta ao Herbário Pe. Dr. Raulino Reitz (CRI) da Universidade do Extremo Sul Catarinense (UNESC) e especialistas. O material fértil foi coletado, herborizado e incorporado ao Herbário Pe. Dr. Raulino Reitz (CRI).

Análise dos dados

Uma curva de rarefação (CAIN; CASTRO, 1959) foi gerada para verificar a suficiência da amostragem na variabilidade florística através do programa computacional PAST versão 1.89 (COLWELL et al., 2004).

Utilizou-se o teste $\chi^{2}$, ao nível de significância de 5\% (ZAR, 1999; CALLEGARI-JACQUES, 2003) para determinar diferenças entre frequência observada e esperada das bromélias nas duas zonas verticais propostas. Os valores esperados de cada espécie epifítica foram obtidos dividindo-se por dois a frequência observada sobre indivíduos forofíticos. As espécies que obtiveram frequências esperadas inferiores a três não foram consideradas. Foi aplicada a correção de Yates $(-0,5)$ ao teste $\chi^{2}$ (CENTENO, 1982).

Para a caracterização da distribuição horizontal foram calculadas as frequências relativas por forófitos $(\mathrm{FRpi}=\mathrm{Npi} / \Sigma \mathrm{Npi})$ e por segmentos de forófitos, ou seja, por copas $($ FRci $=$ Nci $/ \Sigma$ Nci) e fustes $($ FRfi $=$ Nfi $/ \Sigma$ Nfi $)$, onde: Npi $=$ número de forófitos com ocorrência da espécie i epifítica, Nci = número de copas com ocorrência da espécie i epifítica e Nfi = número de fustes com ocorrência da espécie i epifítica. $\mathrm{O}$ valor de importância epifítico (VIe) foi calculado pela média das frequências relativas por copas e por fustes (GIONGO; WAECHTER, 2004).

A relação entre o número de espécies de epífitos e o diâmetro do forófito foi testada através de análise de correlação de Spearman (ZAR, 1999), ao nível de significância a 5\%. A análise foi feita com o auxílio do software PAST, versão 1.89 (HAMMER; HARPER; RYAN, 2009).

\section{RESULTADOS E DISCUSSÃO}

Foram encontradas 18 espécies de bromeliáceas epifíticas (Tabela 1). Entre estas, 11 pertencem à subfamília Tillandsioideae $(61,1 \%)$, representada pelos gêneros 
Tillandsia e Vriesea e sete à subfamília Bromelioideae (38,9\%), sendo Aechmea, Billbergia e Canistrum os gêneros encontrados.

Esses dados assemelham-se aos encontrados por Azeredo (2010) na Floresta Ombrófila Densa Submontana de Terras Baixas, onde foram registradas 20 espécies de bromélias, sendo Vriesea guttata Linden \& André, V. philippocoburgii Wawra, V. psittacina (Hook.) Lindl. e V. rodigasiana E.Morren não encontradas no estudo do PEMJM, enquanto que Aechmea caudata, A. recurvata, e Tillandsia recurvata não foram registradas no estudo de Azeredo (2010) nesse mesmo tipo de formação vegetal.

A família Bromeliaceae distribui-se ao longo de todo o território brasileiro, sendo que todas as espécies amostradas no trabalho são nativas e Aechmea caudata, Aechmea gamosepala,, Canistrum fragrans, Canistrum superbum, Tillandsia mallemontii, T. stricta, Vriesea carinata, V. flammea, V. gigantea, V. incurvata e $V$. vagans $(55,55 \%)$ são endêmicas, tendo como sua principal distribuição a Mata Atlântica (Tabela 3); as demais espécies distribuem-se pelos outros biomas brasileiros, além da Mata Atlântica (Flora do Brasil 2020 em construção, 2016).

Em Ilhota, Santa Catarina, Hoeltgebaum (2003) registrou 19 espécies em um Floresta Submontana e Montana, Bonnet \& Queiroz (2006) registraram 14 espécies (11 em Floresta Submontana) e Azeredo (2008) registrou 25 espécies de bromélias em Fragmento de Floresta Ombrófila Densa Submontana.

Tabela 1. Relação das bromélias encontradas com suas respectivas divisões em nível de subfamília, com a caracterização das estratégias de polinização e dispersão de diásporos, onde: polinização por Ornitofilia (O), Entomofilia (E) e Quiropterofilia (Q); dispersão Zoocórica $(\mathrm{Z})$ e Pogonocórica $(\mathrm{P})$.

\begin{tabular}{lcc}
\hline Espécie & Polinização & Dispersão \\
\hline Bromelioideae & & \\
Aechmea caudata Lindm. & $\mathrm{O}$ & $\mathrm{Z}$ \\
Aechmea gamosepala Lindm. & $\mathrm{E}$ & $\mathrm{Z}$ \\
Aechmea nudicaulis (L.) Griseb. & $\mathrm{O}$ & $\mathrm{Z}$ \\
Aechmea recurvata (Klotzsch) L.B.Sm. & $\mathrm{O}$ & $\mathrm{Z}$ \\
Billbergia zebrina (Herb.) Lindl. & $\mathrm{O}$ & $\mathrm{Z}$ \\
Canistrum fragrans (Linden) Mabb. & $\mathrm{O}$ & $\mathrm{Z}$ \\
Canistrum superbum (Lindm.) Mez. & $\mathrm{O}$ & $\mathrm{Z}$ \\
Tillandsioideae & & \\
\hline Tillandsia mallemontii Glaz.ex Mez & $\mathrm{O}$ & $\mathrm{P}$ \\
Tillandsia geminiflora Brongn. & $\mathrm{O}$ & $\mathrm{P}$ \\
Tillandsia recurvata (L.) L. & $\mathrm{O}$ & $\mathrm{P}$
\end{tabular}




\begin{tabular}{lcc}
\hline Espécie & Polinização & Dispersão \\
Tillandsia stricta Sol. ex Sims & $\mathrm{O}$ & $\mathrm{P}$ \\
Tillandsia tenuifolia L. & $\mathrm{O}$ & $\mathrm{P}$ \\
Tillandsia usneoides (L.) L. & $\mathrm{E}$ & $\mathrm{P}$ \\
Vriesea carinata Wawra & $\mathrm{O}$ & $\mathrm{P}$ \\
Vriesea flammea L.B.Sm & $\mathrm{O}$ & $\mathrm{P}$ \\
Vriesea gigantea Mart. ex Schult. f. & $\mathrm{Q}$ & $\mathrm{P}$ \\
Vriesea incurvata Gaudich. & $\mathrm{O}$ & $\mathrm{P}$ \\
Vriesea vagans (L.B.Sm.) L.B.Sm. & $\mathrm{O}$ & $\mathrm{P}$ \\
\hline
\end{tabular}

Foram registradas 13 espécies no levantamento fitossociológico, totalizando $72,22 \%$ de todas as bromélias encontradas. Aechmea caudata, A. gamosepala, Tillandsia recurvata, Vriesea carinata e $V$. incurvata foram registradas somente no levantamento florístico $(27,78 \%)$.

Os gêneros que apresentaram maior número de espécies foram Tillandsia L. com seis, Vriesea Lindl. com cinco e Aechmea Ruiz \& Pav. com quatro, seguidos por Canistrum E.Morren com duas e Billbergia Thunb. com uma espécie. Esses dados condizem com outros estudos onde os três primeiros gêneros são citados com maior riqueza (TIEPO, 2005; BONNET; QUEIROZ, 2006; COSER, 2008; AZEREDO, 2008; NUNES-FREITAS, 2009). O que pode explicar a representatividade dos gêneros Tillandsia e Vriesea é a maior quantidade e tempo de exposição de luz, pois as espécies desses dois gêneros encontradas no PEMJM preferem locais mais abertos, úmidos e com maior luminosidade; em condições onde o local é mais fechado e com pouca luminosidade, são encontrados em menor abundância (BENZING, 2000; AZEREDO, 2008). Segundo Graham e Andrade (2004) no interior das florestas, o gradiente de luz é de extrema importância, modulando a estratificação vertical em espécies epifíticas, onde algumas delas desenvolvem-se com alta irradiação e outras sob extremo sombreamento, estando intimamente relacionada com a tolerância à baixa irradiação solar dessas plantas (CERVANTES et al., 2005).

Para comprovar a suficiência amostral, foi realizada a curva de rarefação (Figura 2) que indicou estabilização a partir de 34 unidades amostrais (92,9\%), com inclusão posterior de somente uma espécie a partir desse ponto. Essa estabilização ocorreu em aproximadamente metade dos indivíduos amostrados, considerando que o método foi considerado adequado para esse estudo. 
Figura 2. Curva de rarefação para as espécies de bromeliáceas do PEMJM. A curva central representa o número de espécies estimadas e a curva de cima representa intervalo de confiança (IC) de $+95 \%$ sobre o valor observado e a de baixo IC de $-95 \%$ sobre o valor observado.

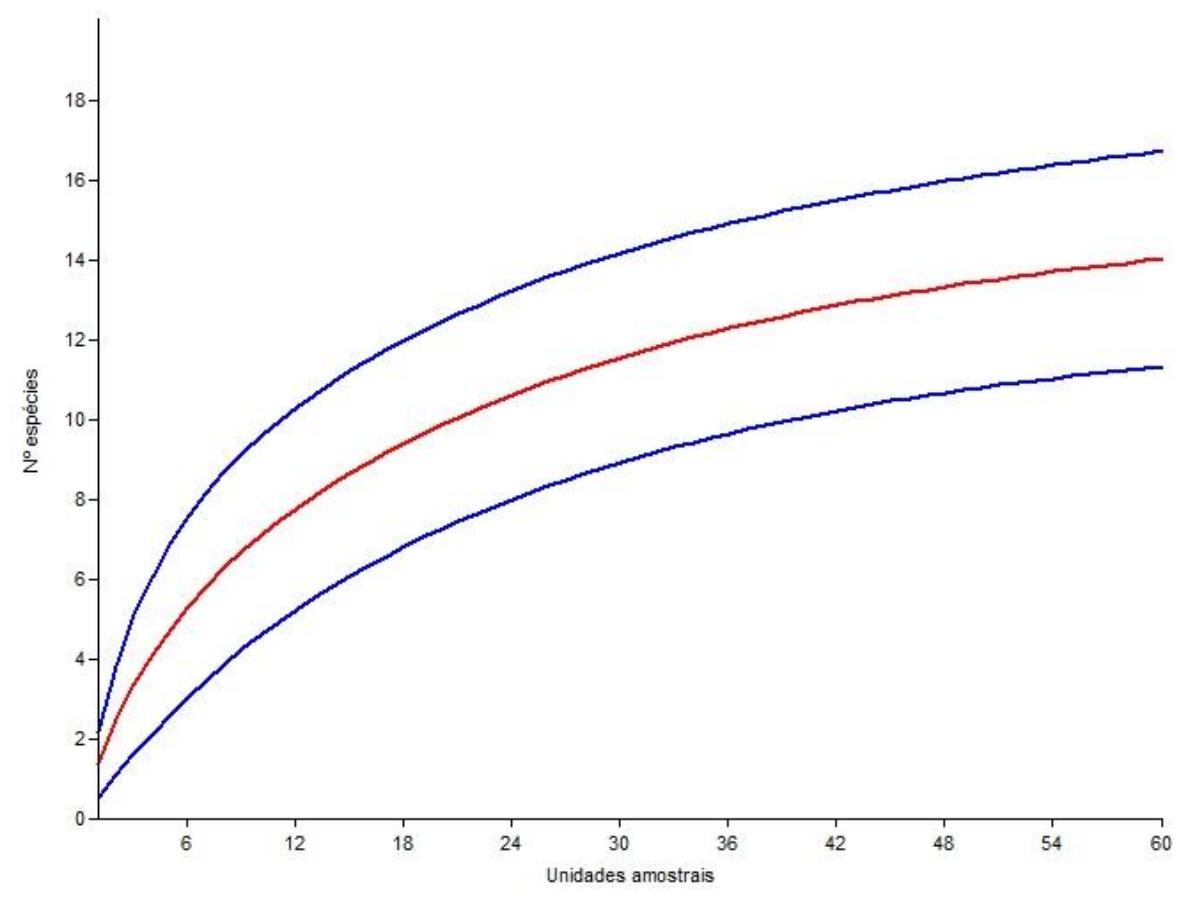

As espécies mais registradas nos forófitos amostrados foram Vriesea gigantea (22 forófitos), Tillandsia stricta (18 forófitos), Aechmea nudicaulis (10 forófitos) e as demais espécies tiverem seu registro em menos de 10 forófitos (Tabela 2).

Em relação à distribuição vertical, as copas foram mais colonizadas que os fustes. Na copa foram obtidos 70 registros, enquanto que no fuste foram 18 registros de bromélias (Tabela 2). Segundo Freiberg (1996), fatores como inclinação dos ramos e acúmulo de material orgânico, como resto de folhas, aumentam a umidade proporcionando maior colonização das bromélias nas copas dos indivíduos arbóreos. A espécie de bromélia com maior ocorrência tanto nos fustes como nas copas dos indivíduos arbóreos foi Vriesea gigantea (27,16\%), seguida por Tillandsia stricta $(22,22 \%)$, Aechmea nudicaulis (12,35\%) e Canistrum superbum (8,64\%). Canistrum fragrans, Aechmea recurvata, Billbergia zebrina, Vriesea flammea e V. vagans só foram encontradas nas copas das árvores e as demais espécies foram encontradas nos fustes e copas.

$\mathrm{O}$ teste $\chi^{2}$ revelou que quatro espécies (Vriesea gigantea, Tillandsia stricta, Aechmea nudicaulis e Canistrum superbum), apresentaram diferenças estatisticamente significativas em frequência das bromélias por local de fixação, revelando a preferência 
dessas espécies pela copa $(\mathrm{p}<0,05)$, sendo que Vriesea gigantea mostrou-se ser a espécie mais adaptada a esse ambiente, já que sua maior colonização foi encontrada na copa das árvores.

Segundo Zotz \& Hietz (2001), a distribuição espacial das bromélias está muito ligada à forma de dispersão de suas sementes, neste caso favorecida pela dispersão anemocórica.

Vriesea gigantea destacou-se como a espécie mais importante, com valor de importância (VIe) equivalente a 25,40\%, seguida por Tillandsia stricta (23,27\%), Canistrum superbum (14,05\%) e Aechmea nudicaulis $(11,27 \%)$ (Tabela 2). As demais espécies variaram o VIe entre 0,1 a 5,6\%.

Suhogusoff (2006) relata que as espécies com elevado VIe são dispersas pelo vento, assim como ocorre com Vriesea gigantea e Tillandsia stricta. Esses dados também corroboram os de Waechter (1998), Piliackas (2001) e Suhogusoff (2002), onde as espécies anemocóricas apresentam alto valor de importância.

Tabela 2. Espécies de bromélias epifíticas amostradas no levantamento fitossociológico do PEMJM, em ordem decrescente de valor de importância, onde: $\mathrm{Npi}=$ número de forófitos ocupados pela espécie epifítica $\mathrm{i}$; Nfi = número de fustes ocupados pelas bromélias epifíticas $\mathrm{i}$; Nci = número de copas ocupadas pelas bromélias epifíticas $\mathrm{i}$; FRpi $=$ frequência relativa da espécie $\mathrm{i}$ nos forófitos; FRci $=$ frequência relativa da espécie i nas copas; FRfi = frequência relativa da espécie i nos fustes; VIe $=$ valor de importância da espécie epifítica i.

\begin{tabular}{lrrrrrrr}
\hline \multicolumn{1}{c}{ Espécie } & Npi & Nfi & Nci & FRpi & FRci & FRfi & VIe \\
\hline Vriesea gigantea & 22 & 4 & 20 & 27,16 & 28,57 & 22,22 & 25,40 \\
Tillandisia stricta & 18 & 5 & 13 & 22,22 & 18,57 & 27,78 & 23,17 \\
Canistrum superbum & 9 & 3 & 8 & 11,11 & 11,43 & 16,67 & 14,05 \\
Aechmea nudicaulis & 10 & 2 & 8 & 12,35 & 11,43 & 11,11 & 11,27 \\
Tillandsia mallemontii & 4 & 1 & 4 & 4,94 & 5,71 & 5,56 & 5,63 \\
Tillandsia usneoides & 3 & 1 & 3 & 3,70 & 4,29 & 5,56 & 4,92 \\
Tillandsia tenuifolia & 3 & 1 & 2 & 3,70 & 2,86 & 5,56 & 4,21 \\
Tillandsia geminiflora & 1 & 1 & 1 & 1,23 & 1,43 & 5,56 & 3,49 \\
Canistrum fragrans & 4 & 0 & 4 & 4,94 & 5,71 & 0,00 & 2,86 \\
Aechmea recurvata & 3 & 0 & 3 & 3,70 & 4,29 & 0,00 & 2,14 \\
Billbergia zebrina & 2 & 0 & 2 & 2,47 & 2,86 & 0,00 & 1,43 \\
Vriesea flammea & 1 & 0 & 1 & 1,23 & 1,43 & 0,00 & 0,71 \\
Vriesea vagans & 1 & 0 & 1 & 1,23 & 1,43 & 0,00 & 0,71 \\
\hline Total & $\mathbf{8 1}$ & $\mathbf{1 8}$ & $\mathbf{7 0}$ & $\mathbf{1 0 0}$ & $\mathbf{1 0 0 , 0 0}$ & $\mathbf{1 0 0 , 0 0}$ & $\mathbf{1 0 0 , 0 0}$ \\
\hline
\end{tabular}


São muitos os fatores envolvidos na distribuição e fixação das bromélias epifíticas, já que na distribuição vertical há variantes microclimáticas, tais como luminosidade, umidade e corrente de ar, acrescidas das variantes físicas proporcionadas pelos forófitos, como quantidade de ramificações, diâmetros e grau de inclinação dos galhos que compõem a copa das árvores (BONNET, 2001, BENAVIDES et al., 2011; WOODS et al., 2014).

A copa é a região mais exposta das árvores e mais sujeita às variações do meio (WAECHTER, 1992). O início da copa apresenta um substrato mais vantajoso para bromélias epifíticas já que nesse local, onde se iniciam as ramificações, os galhos apresentam diâmetros maiores, fornecendo substrato mais seguro e variado. Os diferentes graus de inclinação, juntamente com a espessura desses galhos, propiciam também acúmulo de matéria orgânica, em consequência mais umidade é retida, uma vez que estão mais distanciados do extremo da copa (ter STEEGE; CORNELISSEN, 1989). Outros estudos também mostraram que a distribuição na copa é maior do que no fuste (JOHANSSON, 1974; 1975; ter STEEGE; CORNELISSEN, 1989; NIEDER et al., 1999; SCHÜTZ-GATTI, 2000).

Em relação à estratégia de polinização, a maioria das espécies de bromélias (15 espécies) enquadraram-se como ornitófilas $(83,33 \%)$, utilizando principalmente beijaflores como vetores de pólen, duas espécies (Aechmea gamosepala e Tillandsia usneoides) como entomófilas $(11,11 \%)$, polinizadas normalmente por abelhas e uma espécie (Vriesea gigantea) como quiropterófila (5,56\%) (Tabela 1).

Diversos estudos apontam os beija-flores (ornitofilia) como os principais vetores de pólen, sendo as demais espécies visitadas por morcegos (quiropterofilia) e, em menor quantidade, abelhas (melitofilia) (FISCHER; ARAÚJO, 1995; SAZIMA et al., 1995a; 1996; MARTINELLI, 1997; VARASSIN; SAZIMA, 2000; CANELA; SAZIMA, 2003; ARAÚJO et al., 2004). Todas essas características das bromeliáceas apresentaram atributos descritos para a estratégia da ornitofilia, tais como inflorescências expostas, flores tubulosas, cores contrastantes, inodoras e antese diurna (FAEGRI; PIJL, 1979; MACHADO; SEMIR, 2006). Segundo Snow \& Snow (1986), Sazima et al. (1995b e 1996), Buzatto et al. (2000) e Lopes (2002), a ornitofilia em Bromeliaceae é citada como sendo a principal estratégia de polinização.

Considerando a estratégia de dispersão dos diásporos, a subfamília Bromelioideae tem suas sementes dispersas por animais (endozoocóricas), com frutos 
do tipo baga, correspondendo a 38,9\% (sete espécies), enquanto que as espécies da subfamília Tillandsioideae têm suas sementes dispersas pelo vento, por sementes com plumas (pogonocóricas), correspondendo a 61,1\% (11 espécies) das espécies amostradas (Tabela 1). A predominância das espécies pogonocóricas na maioria dos epífitos é condizente com trabalhos realizados por Gentry e Dodson (1987) e a predominância da subfamília Tillandsioideae pode ser explicada pelos diásporos plumosos poderem vir de áreas vizinhas, propiciando maior riqueza das espécies desta subfamília (BENZING; OTT, 1981). A subfamília Bromelioideae, na qual as espécies possuem seus diásporos carnosos, são dependentes das ações de animais, como morcegos e aves, para que ocorra a dispersão das suas sementes. Essa dependência limita a dispersão das sementes, se por acaso a comunidade não disponibilizar alimento e abrigo para atrair animais dispersores (TIEPO, 2005).

Com relação à obtenção de nutrientes, seis espécies $(33,34 \%)$ foram classificadas como bromélias-atmosfera (Tillandsia) e as demais como bromélias tanque $(66,66 \%)$. Estudos de Fontoura et al. (1997) e Kersten e Silva (2001) mostraram que em Floresta Ombrófila Densa e em formações associadas, onde as chuvas distribuem-se de forma homogênea ao longo do ano, as bromélias formadoras de tanques ou cisternas ocorrem em mais de $80 \%$ das espécies da família. Estudos em Floresta Estacional Semidecidual e Decidual, onde os valores de precipitação anual são similares aos de algumas subformações da Floresta Ombrófila Densa, mas com estação seca bem definida, esses valores são de $63 \%$ para áreas próximas à Floresta Ombrófila Densa (DISLICH; MANTOVANI, 1998). Em trabalhos realizados em Floresta Ombrófila Mista (CERVI; DOMBROWSKI, 1985, CERVI et al., 1988), cerca de 56\% das bromélias formam cisternas ou tanques, indicando que sua ocorrência está mais relacionada à distribuição de chuvas que aos índices pluviométricos anuais.

De modo geral, a riqueza de epífitos vasculares é menor em Floresta Ombrófila Mista que nas unidades vegetacionais sob domínio da Floresta Ombrófila Densa (WAECHTER, 1986; FONTOURA et al., 1997; KERSTEN; SILVA, 2001, 2006) e Floresta Estacional Decidual e Semidecidual (AGUIAR et al., 1981; PINTO et al., 1995; WAECHTER, 1998; DISLICH; MANTOVANI, 1998; BORGO et al., 2002). Essa variação na riqueza está relacionada principalmente à distribuição das chuvas, que na região da Floresta Ombrófila Densa é constante, tendendo a concentrar-se em certas épocas do ano nas florestas estacionais (BORGO; SILVA, 2003). 
As espécies forofíticas mais frequentes foram Aspidosperma parvifolium A.DC., Piptadenia gonoacantha (Mart.) J.F.Macbr., Ocotea odorifera (Vell.) Rohwe e Cryptocarya moschata Nees \& Mart.. O número de espécies de bromélias encontradas sobre os indivíduos forofíticos variou de zero a oito, sendo que o número máximo de espécies foi observado sobre Ocotea indecora (Schott) Mez, seguida de Meliosma sellowii Urb., com sete espécies observadas. A riqueza dos epífitos nestes forófitos pode ser explicada pelo maior substrato disponível e pelo tempo em que ele se encontra disponível à colonização (BENZING, 1990; BONNET; QUEIROZ, 2006; OLIVEIRA et al., 2013).

Os valores obtidos por meio da análise de correlação de Spearman demonstraram que houve forte correlação positiva entre o DAP e riqueza de bromélias ( $r s=0,5356 ; \mathrm{p}<0,001)$, onde árvores com diâmetros maiores apresentam maior riqueza de espécies, ou seja, árvores de maior porte favorecem o estabelecimento das bromélias por oferecer mais substrato (OLIVEIRA et al., 2013).

A relação de bromélias com forófitos de grandes dimensões (maiores alturas e diâmetros) está relacionada com o tempo de exposição dos suportes (forófito), além de maior superfície disponível e existência de microclimas diversos (BENZING, 1990).

Dias (2009) obteve resultados positivos em Floresta Ombrófila Densa Submontana entre abundância e DAP e riqueza e DAP, demonstrando que o diâmetro do forófito influencia o estabelecimento de espécies. Yeaton e Gladstone (1982), Hietz e Hietz-Seifert (1995) e Shaw (2004) acrescentam que esses forófitos maiores oferecem maior área para fixação das plântulas, maior possibilidade de formação de microclimas diversos, como também devem estar a um período maior de tempo crescendo na floresta, resultando em uma forte relação dos grandes indivíduos arbóreos com riqueza de bromélias.

\section{CONCLUSÃO}

Nossos resultados podem elucidar a distribuição de bromélias em fragmentos florestais no Sul de Santa Catarina, contribuindo para projetos de conservação da flora de Bromeliaceae.

Fragmentos florestais são, por muitas vezes, desvalorizados, porém abrigam uma grande diversidade de espécies, sendo áreas potenciais para fonte de propágulos de 
áreas próximas, favorecendo o fluxo gênico entre populações e para manutenção da biodiversidade.

\section{REFERÊNCIAS}

ALVARES, C. A.et al. Köppen's climate classification map for Brazil. Meteorologische Zeitschrift, v. 22, n. 6, p. 711-728, 2014.

AGUIAR, L.W., CITADINI-ZANETTE, V., MARTAU, L.; BACKES, A. Composição florística de epífitos vasculares numa área localizada nos municípios de Montenegro e Triunfo, Rio Grande do Sul, Brasil. Iheringia, Série Botânica, v. 28, p. 55-93, 1981.

ARAÚJO, A. C; FISCHER, E. A; SAZIMA, M. Floração sequencial e polinização de três espécies de Vriesea (Bromeliaceae) na região de Juréia, sudeste do Brasil. Revista Brasileira de Botânica, v. 17, n. 2, p.113-118, 1994.

ARAÚJO, A.C.; FISCHER, E.; SAZIMA, M. 2004. As bromélias na região do Rio Verde. In: Estação Ecológica Juréia- Itatins: Ambiente físico, flora e fauna (MARQUES O.A.V.; DULEBA, W. eds.), 1 ed., Ribeirão Preto, Holos, 2004.

AZEREDO, T. E. V. Bromeliaceae da Fazenda Valo do Paraíso, município de Nova Veneza, Santa Catarina, Brasil. 2008. 65 f. Monografia (Especialização em Gestão de Recursos Naturais) - Universidade do Extremo Sul Catarinense, Criciúma, 2008.

AZEREDO, T. E. V. Diversidade e distribuição de bromélias epifíticas ao longo de um gradiente altitudinal na floresta atlântica do Sul do Brasil. 2010. $54 \mathrm{f}$. Dissertação (Mestrado) - Universidade do Extremo Sul Catarinense, Programa de Pósgraduação em Ciências Ambientais, 2010.

BACK, A. J. Caracterização Climática. In: MILIOLI, G.; SANTOS, R.; CITADINIZANETTE, V. Mineração de carvão, meio ambiente e desenvolvimento sustentável no Sul de Santa Catarina: uma abordagem interdisciplinar. Curitiba: Juruá, 2009. p. 17-33.

BENAVIDES, A.M., VASCO, A., DUQUE, A.J., DUIVENVOORDEN, J.F., 2011. Association of vascular epiphytes with landscape units and phorophytes in humid lowland forests of Colombian Amazonia. J. Trop. Ecol. v.27, p.223-237, 2011.

BENZING, D. H. Bromeliaceae: profile of an adaptive radiation. Cambridge: Cambridge University Press, p. 5-10, 2000.

BENZING, D. H. Vascular Epiphytes. New York: Cambridge University Press. 354p., 1990.

BENZING, D.H.; OTT, D. W. Vegetative reduction in epiphytic Bromeliaceae and Orchidaceae: its origin and significance. Biotropica, v. 13, n. 2, p.131-140, 1981.

BONNET, A. Diversidade e distribuição espacial de bromélias epifíticas em diferentes estádios sucessionais da Floresta Ombrófila Densa, Ilha de Santa Catarina. 2001. 105 f. Dissertação (Mestrado em Biologia Vegetal) - Setor de Ciências Biológicas, Universidade Federal de Santa Catarina, 2001. 
BONNET, A.; QUEIROZ, M. H. Estratificação vertical de bromélias epifíticas em diferentes estádios sucessionais da Floresta Ombrófila Densa, Ilha de Santa Catarina, Brasil. Revista Brasileira de Botânica, v. 29, n.2, p. 217-228, 2006.

BORGO, M.; SILVA, S.M. Epífitos vasculares em fragmentos de Floresta Ombrófila Mista, Curitiba, Paraná, Brasil. Revista Brasileira de Botânica, v.26, p391-401, 2003.

BORGO, M., SILVA, S.M.; PETEAN, M.P. Epífitos vasculares em um remanescente de Floresta Estacional Semidecidual, município de Fênix, PR, Brasil. Acta Biologica Leopoldensia, v.24 p.121-130, 2002.

Flora do Brasil 2020 em construção. Jardim Botânico do Rio de Janeiro. Disponível em: < http://floradobrasil.jbrj.gov.br/ >. Acesso em: 07 Out. 2016

BUZATO, S., SAZIMA, M.; SAZIMA, I. Hummingbird-pollinated floras at three Atlantic Forest sites. Biotropica, v. 32, p. 824-841, 2000.

CAIN, S. A. \& CASTRO, G. M.de O. Manual of vegetation analysis. New York, Hafner, 1959

CÂMARA MUNICIPAL DE CRICIÚMA. Lei Municipal n. ${ }^{\circ}$ 2.856. Criciúma, 2006 Disponível em: < http://camara.plugin.com.br/mostra_lei.asp?lei=2856>. Acesso em: 9 jun. 2009.

CAGLIONI, E. et al. Epífitos vasculares predominantes em zonas ecológicas de forófitos, Santa Catarina, Brasil. Revista de Estudos Ambientais, v. 14, n. 1, p. 28-42, 2012.

CALLEGARI-JACQUES, S. M. Bioestatística: princípios e aplicações. Porto Alegre: Artmed, 1 ed, 256 p., 2003.

CANELA, M.B.F.; SAZIMA, M. Aechmea pectinata: a hummingbird-dependent bromeliad with inconspicuous flowers from the rainforest in south-eastern Brazil. Annals of Botany 92: p.731-737, 2003.

CENTENO, A. J. Curso de estatística aplicado à biologia. Goiânia, Universidade Federal de Goiás, 1982. 188p.

CERVANTES, S.E., GRAHAM, E.A.; ANDRADE, J.L. Light microhabitat, growth and photosynthesis of an epiphytic bromeliad in a tropical dry forest. Plant Ecology, v.179 p.107-118, 2005.

CERVI, A.C.; DOMBROWSKI, L.T.D. Bromeliaceae de um capão de floresta primária do Centro Politécnico de Curitiba (Paraná, Brasil). Fontqueria, v.9, p.9-11, 1985.

CERVI, A.C., ACRA, L.A., RODRIGUES, L., TRAIN, S., IVANCHECHEN, S.L.; MOREIRA, A.L.O.R. Contribuição ao conhecimento das epífitas (exclusive Bromeliaceae) de uma floresta de Araucária do Primeiro Planalto Paranaense. Insula, v.18 p.75-82, 1988.

COLWELL, R. K.; MAO, C. X.; CHANG, J. Interpolating, extrapolating and comparing incidence-based species accumulation curves. Ecology, v.85, n. 10, p. 2727 2727, 2004.

COSER, T. S. Bromeliaceae Juss. dos Campos Rupestres do Parque Estadual do Itacolomi, Minas Gerais, Brasil: Florística e Aspectos fenológicos. 2008. 98 f. Dissertação (Mestrado) - Universidade Federal de Viçosa, Programa de Pós Graduação em Botânica, Minas Gerais, 2008. 
COTTAM, G.; CURTIS, J. T. The use of distance measurements in phytosociological sampling. Ecology, v.37, n.37, p.451-460, 1956.

DIAS, A. S. Ecologia de epífitas vasculares em uma área de Mata Atlântica do Parque Nacional da Serra dos Órgãos, Teresópolis, RJ. 2009. 81 f. Dissertação (Mestrado em Ciências ambientais e florestais). Universidade Federal Rural do Rio de Janeiro. Seropédia, RJ. 2009.

DISLICH, R.; MANTOVANI, W. Flora de epífitas vasculares da Reserva da Cidade Universitária "Armando de Salles Oliveira" (São Paulo, Brasil). Boletim de Botânica da Universidade de São Paulo, v.17, p.61-83, 1998.

EPAGRI/CIRAM - Empresa de Pesquisas Agropecuária e de Extensão Rural de Santa Catarina. Secretaria de Estado do Desenvolvimento Rural e da Agricultura; Centro de Informações de Recursos Ambientais e de Hidrometerologia de Santa Catarina. Dados e informações bibliográficas da Unidade de Planejamento Regional Litoral Sul Catarinense - UPR 8. Florianópolis: EPAGRI, 2001.

FAEGRI, K.; VAN DER PIJL. The principles of pollination ecology. New York, Pergamon Press. 1979.

FILGUEIRAS et al. Caminhamento: um método expedito para levantamentos florísticos qualitativos. Rio de Janeiro, Cad. Geoc., n. 12, p. 39-43, 1994.

FISCHER, E.A.; ARAÚJO, A.C. Spatial organization of a bromeliad community in the Atlantic Rainforest, southeastern Brazil. Journal of Tropical Ecology, v.11, p.550-567, 1995.

FISCHER, E. A. Polinização, fenologia e distribuição espacial de Bromeliaceae numa comunidade de Mata Atlântica, litoral sul de São Paulo. 1994. 80 f. Dissertação de Mestrado, Universidade Estadual de Campinas. Campinas, São Paulo, 1994.

FONTOURA, T. Distribution patterns of five Bromeliaceae genera in Atlantic Rain Forest, Rio de Janeiro State, Brazil. Selbyana, v. 16, n. 1, p. 79-93, 1995.

FONTOURA, T., SYLVESTRE, L. S., VAZ, A.M.S.; VIEIRA, C. M. 1997. Epífitas vasculares, hemiepífitas e hemiparasitas da Reserva Ecológica de Macaé de Cima. In Serra de Macaé de Cima: diversidade florística e conservação da Mata Atlântica (H.C. L.; R.R. G. B,). Editora do Jardim Botânico, Rio de Janeiro, p.89-101, 1997.

FREIBERG, M. Spatial distribution of vascular epiphytes on three emergent Canopy trees in French Guiana. Biotropica, v.28, n.3, p.345-355, 1996.

GENTRY, A.H.; DODSON, C.H. Contribution of nontrees to species richness of a tropical Rain Forest. Biotropica, v.19, n.2, p.149-156. 1987.

GIONGO, C.; WAECHTER, J. L. Composição florística e estrutura comunitária de epífitos vasculares em uma floresta de galeria na Depressão Central do Rio Grande do Sul. Revista Brasileira de Botânica, v.27, n.3, p.563-572, 2004.

GIVNISH, T. J. et al. Phylogeny, adaptative radiation, and historical biogeography of Bromeliaceae inferred from $n d h \mathrm{~F}$ sequence data. Aliso, v.23, p.3-26, 2007.

GRAHAM, E. A.; ANDRADE, J. L. Drought tolerance associated with vertical stratifi cation of two co-occurring epiphytic bromeliads in a tropical dry forest.

American Journal of Botany, 91:699-706, 2004. 
HAMMER, O; HARPER, D. A. T.; RYAN, P. D. PAST: PAleontological Statistics, versão 1.89, 2009. Disponível em: http://folk.uio.no/ohammer/past.. Acesso em: 10 out. 2009.

HIETZ, P.; HIETZ-SEIFERT, U. Composition and ecology of vascular epiphyte communities along an altitudinal gradient in central Veracruz, México. Journal of Vegetation Science, v. 6, p. 487-498, 1995.

HOELTGEBAUM, M. P. Composição florística e distribuição espacial de bromélias epifíticas em diferentes estádios sucessionais da floresta ombrófila densa - Parque Botânico do Morro Baú - Ilhota/SC. 2003. 138f. Dissertação (Mestrado em Biologia Vegetal)- Universidade Federal de Santa Catarina, Florianópolis, 2003.

JOHANSSON, D. R. Ecology of vascular epiphytes in West African rain forest. Acta Phytogeographica Suecica, v.59, p.1-136, 1974.

JOHANSSON, D.R. Ecology of epiphytic orchids in West African rain forest. Am. Orchid. Soc. Bull, v.44, p.125-136, 1975.

KERSTEN, R. A. Epifitismo vascular na bacia do Alto Iguaçu, Paraná. 2006. $231 \mathrm{f}$. Tese (Doutorado em Engenharia Florestal) - Universidade Federal do Paraná, Curitiba, 2006.

KERSTEN, R. A.; SILVA, S. M. Composição florística e estrutura do componente epifítico vascular em floresta da planície litorânea na Ilha do Mel, Paraná, Brasil. Revista Brasileira de Botânica, v.24, n.2, p.213-226, 2001.

KERSTEN, R. A.; Epífitas vasculares - Histórico, participação taxonômica e aspectos relevantes, com ênfase na Mata Atlântica. Hoehnea, São Paulo, v. 31, n.1, p. 9-38, 2010.

KRESS, W.J. The systematic distribution of vascular epiphytes: an update. Selbyana, v.9, p.2-22, 1986.

LOPES, A.V.F. 2002. Polinização por beija-flores em remanescente da Mata Atlântica Pernambucana, Nordeste do Brasil. Revista Brasileira de Botânica, v.29, n.3, p.12-19, 2002.

MACHADO, C.G.; SEMIR, J. Fenologia da floração e biologia floral de bromeliáceas ornitófilas de uma área da Mata Atlântica do sudeste brasileiro. Revista Brasileira de Botânica, v.29, p.163-174, 2006.

MARTINELLI et al. Mata Atlântica brasileira: lista de espécies, distribuição e conservação. Rodriguésia, v.59, n.1, p.209-258, 2008. Disponível em: <http://www.jbry.gov.br/publica/rodriguesia/rodrig59_1/061-07.pdf>. Acesso em: 12 jun. 2008.

MARTINELLI, G. 1997. Biologia reprodutiva de Bromeliaceae na Reserva Ecológica de Macaé de Cima. In: Serra de Macaé de Cima: Diversidade Florística e Conservação em Mata Atlântica (H.C.; R. R. G. B. eds.). Rio de Janeiro, Jardim Botânico do Rio de Janeiro, p.213-250, 1997.

MARTINELLI, G. Manejo de populações e comunidades vegetais: um estudo de caso na conservação de Bromeliaceae. In: ROCHA, C. F. D; BERGALLO, H. G; SLUYS, M. V; ALVES, M. A. S. Biologia da Conservação. São Carlos: Rima, v.21, p. 479503, 2006. 
MOREIRA, B. A.; WANDERLEY, M. G. L.; BARROS, M. A.V. C. Bromélias: importância ecológica e diversidade. Taxonomia e morfologia - Curso de Capacitação de Monitores. São Paulo: Instituto de Botânica, 12 p, 2006.

NIEDER, J.; ENGWALD, S.; BARTHLOTT, W.. Patterns of neotropical epiphyte diversity. Selbyana, v.20, n.1, p.66-75, 1999.

NUNES-FREITAS, A.F., ROCHA-PESSÔA, T.C., DIAS, A.S., ARIANI, C.V.; ROCHA, C.F.D. Bromeliaceae of Ilha Grande: species checklist Review. Biota Neotropica, v.9, n.2, 2009.

OLIVEIRA, L. C.; PADILHA, P. T.; DALMOLIN, E. B.; AZEREDO, T. E. V.; CITADINI-ZANETTE, V. Componente epifítico vascular de um Fragmento Florestal Urbano, município de Criciúma, Santa Catarina, Brasil. Biotemas, Florianópolis, v. 26, n. 2, p. 33-44, 2013.

PADILHA, P. T.; SANTOS, R.; CUSTÓDIO, S. Z.; OLIVEIRA, L. C.; SANTOS, R.; CITADINI-ZANETTE, V. Comunidade epifítica vascular do Parque Estadual da Serra Furada, sul de Santa Catarina, Brasil. Ciência e Natura, v.37, n.1, p.64-78, 2015.

PAULA, C. C.; SILVA, H. M. P. Cultivo prático de bromélias. Viçosa: UFV, 106 p, 2004.

PILIACKAS, J.M. Fitossociologia da comunidade epifítica vascular do manguezal do Rio das Bicas (Picinguaba, Ubatuba, São Paulo, SP). 2001. 112 f. Tese de Doutorado, Instituto de Biociências da Universidade Estadual Paulista "Julio de Mesquita Filho", Rio Claro, 2001.

PINTO, A.C.R., DEMATTÊ, M.E.S.P.; PAVANI, M.C.M.D. Composição florística de epífitas (Magnoliophyta) em fragmento de floresta no município de Jaboticabal, SP, Brasil. Científica, v.23, p.283-289, 1995.

REITZ, R. Bromeliáceas e a malária: bromélia endêmica. Flora Ilustrada Catarinense Brom., v.1, p.1-518, 1983.

ROCHA, E. Estrutura da sinúsia herbácea terrícola do Paque Ecológico Municipal José Milanese, Criciúma, Santa Catarina. 2007. 32f. Monografia (Graduação em Ciências Biológicas) - Universidade do Extremo Sul Catarinense, 2007.

SAZIMA I.; BUZATO, S.; SAZIMA, M. An assemblage of hummingbird-pollinated flowers in Montane Forest in Southeastern Brazil. Botanica Acta, v.109, p.149-160, 1996.

SAZIMA, I., BUZATO, S.; SAZIMA, M. The Sawbilled Hermit Ramphodon naevius and its flowers in southeastern Brazil. Journal of Ornithology, v. 136, p.105-206, 1995b.

SAZIMA, M.; BUZATO, S.; SAZIMA, I. Bat pollination of Vrisea in southeastern Brazil. Bromélia, v.2, p.29-37, 1995a.

SCHÜTZ-GATTI, A. L. S. 2000. O componente epifítico vascular na reserva natural Salto Morato, Guaraqueçaba - PR. Dissertação de Mestrado em Botânica. Universidade Federal do Paraná, PR.

SHAW, D. C. Vertical organization of canopy biota. In: LOWMAN. M.D.; REINKER, H. B. Forest Canopies. London. Elsevier Academic, p.73-101, 2004. 
SILVA, R.T. Florística e estrutura da sinúsia arbórea de um fragmento urbano de floresta ombrófila densa do município de Criciúma, Santa Catarina. 2006. 61f. Dissertação (Mestrado em Ciências Ambientais) - Programa de Pós Graduação em Ciências Ambientais, Universidade do Extremo Sul Catarinense, Criciúma, 2006.

SNOW, D.W.; SNOW, B.K. Feeding ecology of hummingbirds in the Serra do Mar, southeastern Brazil. El Hornero, v.12, p.286-296, 1986.

STEEGE, H. TER.; CORNELISSEN, J.H.C. Distribution and ecology of vascular epiphytes in lowland rain forest of Guyana. Biotropica, v.21, n.4, p.331-339, 1989.

STEHMANN, J. R. et al. (Ed.). Plantas da Floresta Atlântica. Rio de Janeiro: Jardim Botânico do Rio de Janeiro, 2009. 516 p.

SUHOGUSOFF, V. G. Caracterização de padrões de degradação ambiental baseada na avaliação florística e fitossociológica arbórea e de epífitas vasculares em dois manguezais no município de Ubatuba - SP - Brasil. 2002. 92 f. Dissertação de Mestrado, Universidade de Guarulhos, Guarulhos, 2002.

SUHOGUSOFF, V. G. Epífitas vasculares do Parque Estadual da Ilha Anchieta (PEIA), Ubatuba, SP, Brasil: 170 f. Composição florística, fitossociologia e aspectos de ecofisiologia. Tese (Doutorado em Biodiversidade Vegetal e Meio Ambiente) Instituto de Botânica da Secretaria de Estado do Meio Ambiente, São Paulo, 2006.

TIEPO, E. N. Colonização de Bromélias Epifíticas em três estádios sucessionais florestais na Unidade de Conservação Ambiental Desterro, Ilha de Santa Catarina. 2005. 69 f. Dissertação (Mestrado) - Universidade Federal de Santa Catarina, Programa de Pós Graduação em Biologia Vegetal, Florianópolis, 2005.

VARASSIN, I.G.; SAZIMA, M. Recursos de Bromeliaceae utilizados por beija-flores e borboletas em Mata Atlântica no sudeste do Brasil. Boletim do Museu de Biologia Mello Leitão, v.11 n.12 p.57-70, 2000.

WAECHTER, J. L. Epífitos vasculares da mata paludosa do Faxinal, Torres, Rio Grande do Sul, Brasil. Iheringia, Série Botânica, v.34 p.39-49, 1986.

WAECHTER, J. L. O epifitismo vascular na Planície Costeira do Rio Grande do Sul. 1992. 163 f. Tese (Doutorado em Ecologia e Recursos Naturais) - Universidade Federal de São Carlos (UFSCar), São Paulo, 1992.

WAECHTER, J. L. Epifitismo em uma floresta de restinga do Brasil subtropical. Ciência e Natura, v.20, p.43-66, 1998.

WANDERLEY, M. G. L.; MARTINS, S. E. Bromeliaceae.In: WANDERLEY, M. G. L.; SHEPHERD, G. J.; MELHEM, T. S.; GIULIETTI, A. M.(Coord.). Flora Fanerogâmica do Estado de São Paulo. SP: Instituto de Botânica, 2007. p.39-61.

WOODS, C. L., CARDELÚS, C. L., DEWALT, S. J. Microhabitat associations of vascular epiphytes in a wet tropical forest canopy. J. Ecol. v.103, n.2, p.421-430, 2014.

YEATON, R. I.; GLADSTONE, D. E. The pattern of colonization of epiphytes on Calabash Trees (Crescentia alata HBK.) in Guanacaste Province, Costa Rica. Biotropica, v.14, n.2, p. 137-140. 1982.

ZAR, J. H. Biostatistical analysis. New Jersey: Prentice Hall, 4 ed. 1999. 459p. 
Revista Tecnologia e Ambiente, v. 22, 2016, Criciúma, Santa Catarina

ISSN 1413-8131

ZOTZ, G.; HIETZ, P. The physiological ecology of vascular epiphytes: current knowledge, open questions. Journal of Experimental Botany, v.52, n.364, p.20672078, 2001.

ZOTZ, G. The systematic distribution of vascular epiphytes - A critical update. Botanical Journal of the Linnean Society, v. 171, p. 453-481, 2013. 